\title{
Histological changes of human placenta in early intrauterine growth restriction with and without preeclampsia
}

\section{Original Article}

\author{
Eman Mohamed Askar', Sally Ahmed Selim ${ }^{1}$,Hoda Sibai ${ }^{2}$ \\ ${ }^{1}$ Department of Histology and Cell Biology, 'Department of Obstetrics and Gynecology, \\ Faculty of Medicine, Zagazig University, Zagazig, Egypt.
}

\begin{abstract}
Background: Intra uterine growth restriction (IUGR) is a common pregnancy complication, pre-eclamsia (PE) is an important cause of this complication and is responsible for maternal and fetal morbidity and mortality. Idiopathic intrauterine growth restriction without obvious causes is not uncommon.

Objective: The aim of this study is to examine the placental histology in both conditions trying to find specific criteria for each disorder.

Materials and Methods: This study was conducted on three groups; group I was the control group, group II was preeclampsia induced IUGR (PE-IUGR) group and group III was idiopathic IUGR (I-IUGR). Each group contained 15 placentas. Placental specimens from each group were analyzed histopathologically and immunohistochemically.

Results: we found that PE-IUGR and I-IUGR cases in this study share common histological changes suggesting a similar pathogenesis. Maternal mal-perfusion lesions predominated in PE-IUGR. Findings consistent with fetal vascular malperfusion were higher in I-IUGR. Hofbauer cells (HBC) were increased in both PE-IUGR and I-IUGR.

Conclusion: abnormal utero-placental blood vessels and utero-placental insufficiency and the resulting histological changes in the chorionic villi, and chronic inflammatory lesions may be the primary disease processes related to the placental pathology of PE-IUGR and I-IUGR.
\end{abstract}

Key Words: Decidual vasculopathy, fetal vascular obstruction intrauterine growth restriction, placenta, preeclampsia.

Revised: 09 May 2019, Accepted: 20 June 2019

Corresponding Author: Sally Ahmed Selim, Ph.D, Department of Histology and Cell Biolog, Faculty of Medicine, Zagazig University, Zagazig, Egypt, Tel.: 01022544811, E-mail: sa.selim73@gmail.com

ISSN:2536-9172, June 2019, Vol. 3, No. 1

\section{INTRODUCTION}

The placenta modulates the in utero environment to promote optimal fetal development. The placental blood vessels are responsible for metabolic exchange between the mother and fetus, which is essential for proper fetal growth. Impairment of this function, can lead to intrauterine growth restriction ${ }^{[1]}$. Intra uterine growth restriction (IUGR) is defined as a failure of the fetus to reach its genetic growth potential ${ }^{[2]}$. IUGR may be caused by maternal, fetal, placental and environmental factors ${ }^{[3]}$.

The prevalence of IUGR in the general population worldwide was estimated to be $7-15 \%$, while in developing countries - including Egypt - it reaches up to 30\% and constitutes $50-60 \%$ of low birth weight neonates ${ }^{[4,5]}$. Early onset preeclampsia is a major cause of IUGR, but normotensive IUGR with no apparent causes is not uncommon $^{[6]}$.

Preeclampsia (PE) is defined as a new onset of hypertension (more than 140/90) and proteinuria in the second half of pregnancy ${ }^{[7]}$. It is the commonest complication of pregnancy worldwide. It is also the major causes of maternal and perinatal morbidity and mortality, especially in low- and middle-income countries ${ }^{[8,9]}$.

Risk factors for PE include pregnancy at the extremes of maternal age, obesity, preexisting hypertension, diagnosis of preeclampsia in a previous pregnancy, diabetes or renal disease, nulliparity, multiple gestation, and preexisting autoimmune diseases such as antiphospholipid antibody syndrome and systemic lupus erythematosus ${ }^{[10]}$.

PE can be classified as early and late onset preeclampsia. The late onset type develops after the 34 th week of gestation and is characterized by normal fetal growth; the early onset type develops before the 34th week of gestation and is characterized by $\mathrm{IUGR}^{[11]}$. Late onset PE is considered a maternal not a placental disease with little or no changes in the placental morphology ${ }^{[12]}$.

PE is characterized by placental ischemia, maternal immune activation, increased arterial resistance, decreased production of vasodilators, and maternal endothelial dysfunction. These factors, combined with the maternal hypertension, often result in $\operatorname{IUGR}^{[7,10, \text { and 13] }}$.

Hofbauer cells (HBCs) are villous macrophage of fetal 
origin, they arise from villous mesenchymal stem cells, and later on they develop from fetal monocytes. They decrease in number after the first trimester and can be detected immunohistochemically using special markers like CD 163 and CD 68 ${ }^{[14]}$. Their role in PE and IUGR is a matter of controversy and is not well investigated.

The placenta responds to different insults by reaction patterns involving the maternal and fetal vasculature and villous structure. These patterns are not specific; both PE and IUGR share several lesions but with variable degrees ${ }^{[15]}$. Many researchers focused on PE induced IUGR (PE-IUGR) rather than idiopathic intrauterine growth restriction (I-IUGR) and still much to be known about the differences and similarities between the two conditions.

In this study we used some of the placental reaction patterns that had been accepted by the international consensus for placental diagnosis. Placental lesions were classified into placental vascular processes (maternal and fetal), placental inflammatory-immune processes and other placental processes ${ }^{[16]}$. Placental vascular processes including villous changes were the focus of our study. We correlated these lesions with two important placental syndromes; early onset preeclampsia complicated by IUGR (PE-IUGR) and early onset idiopathic IUGR (I-IUGR). Both conditions are characterized by maternal and fetal vascular changes $^{[17]}$. Up to the best of our knowledge, this study was the first to apply these criteria in examining placentas from Egyptian patients. We conducted this study on 30 cases of preeclampsia complicated by IUGR (PE-IUGR, idiopathic IUGR (I-IUGR) and 15 normal pregnancy. The placental histology in both conditions was examined trying to correlate specific histopathological criteria with the clinical presentation.

\section{MATERIALS AND METHODS}

\section{Study groups}

This study was conducted in the faculty of medicine Zagazig University. All pregnant females $(n=45)$ provided written informed consents before participating in the study. Approval for the study was obtained from the Local Ethics Committee.

\section{Patient criteria}

1- Maternal age between 20-35years, primi-gravida, singleton pregnancy.

2- The gestational age was calculated from the last menstrual period or from first trimester ultrasound examination.

3- Cases with preexisting maternal illness such as hypertension, gestational diabetes mellitus, renal, cardiac, hepatic and autoimmune disorders were excluded from the study.

4- Cases of infants with congenital anomalies, chromosomal aberrations and intrauterine infections were excluded from the study.

5- Cases complicated with stillbirth were excluded from the study.

All the cases were delivered in the gynecology and obstetrics department, Zagazig university hospitals by elective caesarean section without induction of labor to minimize the effect of uterine contraction and oxidative stress on placental histology.

1) Group I $(n=15)$ : represented the control group including 15 placentas from women with normal blood pressure, blood glucose level, normal clinical examination. The fetal birth weights were above the 10th percentile for the gestational age. Birth weight percentiles were determined according to Egyptian growth curves for boys and girls[18,19]

2) Group II(PE-IUGR) $(n=15)$ : represented the IUGR that complicates preeclampsia, the group comprised 15 placentas from early onset preeclampsia patients. The fetal birth weights were below the 10th percentile for the gestational age ${ }^{[18,19]}$. PE was defined as a blood pressure of greater than $140 / 90 \mathrm{mmHg}$ on two occasions greater than 6 hours apart and proteinuria of $>300 \mathrm{mg} / 24$ hours in the second half of pregnancy in a previously normotensive woman $^{[20]}$

3) Group III (I-IUGR) $(n=15)$ : represented the idiopathic IUGR group, it includes 15 placentas from patients with normal blood pressure, normal blood glucose level and normal clinical examination. The fetal birth weights were below the 10th percentile for the gestational age ${ }^{[18,19]}$.

\section{Histopathological examination}

Immediately after delivery, two samples were taken from each placenta $(n=90)$. Full thickness specimens were taken from the central area near the cord insertion and from the central two thirds of the placenta. Samples were taken from areas that appeared normal by gross examination, and not from areas containing infarction or gross fibrin deposition. Specimens were rapidly fixed in $10 \%$ neutral formalin at $\mathrm{pH} 7.2$ for $24 \mathrm{hr}$., dehydrated in ascending grades of ethyl alcohol, cleared in xylene and embedded in paraffin wax for $24 \mathrm{hr}$. Sections of $5 \mu \mathrm{m}$ were cut, mounted on glass slides and stained with routine heamtoxyline\& eosin (H\&E), Mallory's trichrome (MTC) stain and periodic acid-schiff (PAS) stain ${ }^{[21]}$. 


\section{Immunohistochemistry}

Immunohistochemistry was done to identify Hofbauer cells by using an antibody against CD68. Paraffin sections $(5 \mu \mathrm{m}$ thick) were used, immunostaining was done using mouse antihuman CD68 antibodies PG-M1, Cat. No. M0876 [1:1200, life trade, Dako, Denmark]. Mayer's heamatoxylin was used as a counterstain. The staining pattern was cytoplasmic and appeared as a brown color ${ }^{[22]}$

\section{Morphometric and statistical study}

Leica Quin 500 Image Analyzer (Leica Ltd, Cambridge, UK) in the Image Analyzing Unit of the Pathology Department, Faculty of Dentistry, Cairo University (Egypt) was used. The following parameters were measured for each group.

1) Villous diameter: the mean diameter of terminal villi was measured in $\mu \mathrm{m}$ and used as an indicator distal villous hypoplasia.

2) Number of syncytial knots.

3) Fetal vascular obstructive lesions.

4) Decidual blood vessels changes.

5) Surface area of collagen (MTC stained sections).

6) Surface area of fibrinoid (PAS stained sections).

7) Number of HBCs.

Ten non-overlapping fields (X400) were measured for each parameter. A mean value is calculated for each slide. The data obtained were expressed as means $\left(\mathrm{X}^{-}\right)$ and standard deviations (SD) and subjected to statistical analysis using one-way analysis of variance (ANOVA Excel 2013 Microsoft) for comparison between the different groups (more than two groups). Followed by least significant difference test (LSD), for comparison between different groups, i.e. to find the statistical difference between groups when ANOVA was statistically significant $(P$ value $<0.05$ was considered statistically significant $)^{[23]}$. All the statistical analyses were done using the Statistical Package for the Social Sciences (SPSS) version 16 packages (https://spss-64bits.en.softonic.com)

\section{RESULTS}

\section{Clinical data}

All the clinical data were summarized in table 1. The results revealed that the gestational age, fetal birth weight and placental weight were significantly lower in the
PE-IUGR and I-IUGR groups when compared with the control group. The gestational age was significantly lower in the in the PE-IUGR group when compared with the I -IUGR group (Table 1).

\section{Histological examination}

\section{$H \& E$-stained sections:}

Control group I; showed placental villi of different types (stem, intermediate and terminal) cut in different planes (Fig. 1-A). These villi were supported by a core of mesenchymal connective tissue, which contained numerous fetal capillaries lined by flat endothelial cells. Each villous was lined by syncytiotrophoblasts and aggregations of many syncytial nuclei to form syncytial knots were noticed (Fig. 1-B). These villi were separated by intervillous space containing maternal blood and little amount acidophilic materials or fibrinoid(Fig. 1-A\&B). Within the stem villous stroma, the fetal capillaries were lined by simple squamous endothelial cells containing flattened nuclei (Fig. 1-C).

Pre-eclamptic intrauterine growth restriction (PE-IUGR) group II; revealed the presence of amorhous acidophilic areas in the core of some stem and terminal villi, numerous syncytial knots with sprouts were found. Avascular and low vascular villi were seen (Fig. 1-D, E and F). Exfoliated syncytial knots, acidophilic amorphous material (fibrinoid) and maternal blood were observed in the intervillous space. (Fig. 1-D and E). Several terminal villi with thickened syncytio-vascular membrane and others with thin membrane were seen. Within the villous stroma, vacuolated cells with darkly stained nuclei and macrophage-like cells with strong acidophilic cytoplasm were seen (Fig. 1-E and F). The chorionic plate showed engorged fetal blood vessel and scattered extravillous trophoblasts. Some fetal blood vessels had thick wall with some vacuolated cells (Fig. 1-G).Decidual blood vessels showed many changes; some vessels were engorged with blood, others had abnormal endothelial lining, the wall of some blood vessels was replaced by acellularacidiophilic material, the lumens were partially or totally obliterated by amorphous acidophilic material and vacuolated cells (foam cells) were seen around the wall of some vessels (Fig. 1-H). Normal decidual blood vessels were also found.

Idiopathic intrauterine growth restriction (I-IUGR) group III; revealed the chorionic plates contained amorphous acidophilic areas and numerous vacuolated cells with darkly stained nuclei. Several forms of placental villi can be demonstrated. Most of them appeared widely separated (Fig. 2-A). Some villi had highly cellular core and some contained amorphous acidophilic areas. Some villi contained numerous capillaries and others were avascular. Several terminal villi had thickened syncytio-vascular membrane and increased syncytial knots in some areas, in their stroma, numerous vacuolated cells with darkly stained 
nuclei can be observed. The inter-villous spaces contained acidophilic material (fibrinoid) and maternal blood (Fig. 2- B). Some fetal blood vessels had thick wall, their lumens were engorged with blood and contained amorphous material partially obliterating the lumen (Fig. 2- C). The placental septum and the decidual plate showed numerous extra-villous trophoblasts; irregular or polygonal in shape with darkly stained nuclei and also vacuolated cells with central nuclei, some maternal blood vessels were engorged and contained amorphous material patially obliterating the lumen (Fig. 2-D and E).

\section{PAS, MT and CD68 immuno-expressed-stained sections:}

PAS stained section, showed a weak or faintly positive PAS reaction in the core of villi and basement membrane of the trophoblasts in group I (Fig. 3-A) while a strong reaction in same areas plus the walls of blood vessel and their lumens in other two groups (Fig. 3-B and C).

MT-stained sections, showed delicate connective tissue core or minimal amount of collagen fibers in terminal villi and thick stroma of stem villi (Fig. 3-D). Abundant and extensive amount of collagen fibers were detected in the different villi of group II and III (Fig. 3-E and F).

CD68 immuno-expressed-stained sections, showed few +ve cells or Hofbauer cells were detected in the villous stroma near the syncytio-vascular membrane as a brown immune-staining (Fig. 3-G). Numerous of these cells were seen in other groups (Fig. 3-H and I).

\section{Morphometric and statistical study}

Placental histological lesions are summarized in (Table 2).

In the PE-IUGR group, all the measured parameters were significantly higher when compared with the control group except for the villous diameter which is significantly lower when compared with the control group. The number of syncytial knots and the fibrinoid surface area were significantly higher in the PE-IUGR when compared with the I-IUGR group.

In the I-IUGR group, the fetal vascular obstructive lesions, decidual-arteriopathy, collagen surface area and the number of Hofbauer cells were significantly higher and the villous diameter was significantly lower when compared with the control group. The number of syncytial knots and the fibrinoid surface area were not statistically significant when compared with the control group. The fetal vascular obstructive lesions and the collagen surface area were significantly higher and the villous surface area was significantly lower when compared with the PE-IUGR group.

Table 1: Some maternal and fetal enrollment data

\begin{tabular}{|c|c|c|c|c|c|c|}
\hline Parameter & Group & Mean & SD & $\mathrm{F}$ & $\mathrm{P}$ & LSD \\
\hline Gestational Age & $\begin{array}{l}\text { Control } \\
\text { PE-IUGR } \\
\text { I-UGR }\end{array}$ & $\begin{array}{l}37.25 \\
29.75 \\
35.88\end{array}$ & $\begin{array}{l}1.04 \\
1.04 \\
0.64\end{array}$ & 149.84 & $<0.001^{* *}$ & $\begin{array}{l}<0.001^{* *_{1}} \\
<0.01^{* *_{2}} \\
<0.001^{* * 3}\end{array}$ \\
\hline Birth weight & $\begin{array}{l}\text { Control } \\
\text { PE-IUGR } \\
\text { I-UGR }\end{array}$ & $\begin{array}{l}3.20 \\
1.96 \\
2.20\end{array}$ & $\begin{array}{l}0.12 \\
0.35 \\
0.31\end{array}$ & 44.55 & $<0.001 * *$ & $\begin{array}{l}<0.001^{* *_{1}} \\
<0.001^{* *_{2}} \\
>0.05 \mathrm{NS}^{3}\end{array}$ \\
\hline Placental weight & $\begin{array}{l}\text { Control } \\
\text { PE-IUGR } \\
\text { I-UGR }\end{array}$ & $\begin{array}{l}481.27 \\
381.70 \\
314.80\end{array}$ & $\begin{array}{l}22.12 \\
24 \\
34.8\end{array}$ & 73.98 & $<0.001 * *$ & $\begin{array}{l}<0.001^{* *_{1}} \\
<0.001^{* *_{2}} \\
<0.001^{* *_{3}}\end{array}$ \\
\hline
\end{tabular}

$\begin{array}{lll}\text { SD: Standard deviation } & \text { F: ANOVA test } & \text { LSD: Least significant difference } \\ \text { P1: Control versus PE-IUGR } & \text { P2: Control versus IUGR } & \text { P3: PE-IUGR versus IUGR } \\ \text { NS: Non significant }(P>0.05) & * \text { : Significant }(P<0.05) & * * \text { : Highly significant }(P<0.01)\end{array}$


Table 2: Placental findings in women with IUGR with and without pre-eclampsia

\begin{tabular}{|c|c|c|c|c|c|c|}
\hline Parameter & Group & Mean & $\mathrm{SD}$ & $\mathrm{F}$ & $P$ & LSD \\
\hline $\begin{array}{l}\text { Collagen surface } \\
\text { area }\end{array}$ & $\begin{array}{c}\text { Control } \\
\text { PE-IUGR } \\
\text { I-UGR }\end{array}$ & $\begin{array}{c}8.96 \\
13.58 \\
16.14\end{array}$ & $\begin{array}{l}0.80 \\
1.72 \\
1.64\end{array}$ & 50.39 & $<0.001^{* *}$ & $\begin{array}{l}<0.001^{* * 1} \\
<0.001^{* *_{2}} \\
<0.01^{* * 3}\end{array}$ \\
\hline Knots & $\begin{array}{c}\text { Control } \\
\text { PE-IUGR } \\
\text { I-UGR }\end{array}$ & $\begin{array}{c}5.81 \\
17.52 \\
5.76\end{array}$ & $\begin{array}{l}0.43 \\
4.39 \\
0.47\end{array}$ & 55.94 & $<0.001^{* *}$ & $\begin{array}{c}<0.001^{* * 1} \\
>0.05 \mathrm{NS}^{2} \\
<0.001^{* * 3}\end{array}$ \\
\hline Fetal Vasculopathy & $\begin{array}{c}\text { Control } \\
\text { PE-IUGR } \\
\text { I-UGR }\end{array}$ & $\begin{array}{l}0.75 \\
3.50 \\
5.38\end{array}$ & $\begin{array}{l}0.71 \\
1.20 \\
1.41\end{array}$ & 33.21 & $<0.001^{* *}$ & $\begin{array}{c}<0.001^{* * 1} \\
<0.001^{* * 2} \\
<0.01^{* * 3}\end{array}$ \\
\hline Decidualvasculopathy & $\begin{array}{c}\text { Control } \\
\text { PE-IUGR } \\
\text { I-UGR }\end{array}$ & $\begin{array}{l}0.88 \\
4.38 \\
2.75\end{array}$ & $\begin{array}{l}0.64 \\
0.92 \\
1.04\end{array}$ & 31.72 & $<0.001^{* *}$ & $\begin{array}{l}<0.001^{* * 1} \\
<0.001^{* * 2} \\
<0.01^{* * 3}\end{array}$ \\
\hline Villous Diameter & $\begin{array}{c}\text { Control } \\
\text { PE-IUGR } \\
\text { I-UGR }\end{array}$ & $\begin{array}{l}58.62 \\
55.39 \\
51.08\end{array}$ & $\begin{array}{l}3.53 \\
2.67 \\
1.75\end{array}$ & 15.18 & $<0.001^{* *}$ & $\begin{array}{l}<0.05^{* * 1} \\
<0.001^{* * 2} \\
<0.001^{* *_{3}}\end{array}$ \\
\hline Fibrinoid surface area & $\begin{array}{c}\text { Control } \\
\text { PE-IUGR } \\
\text { I-UGR }\end{array}$ & $\begin{array}{c}5.76 \\
10.63 \\
5.47\end{array}$ & $\begin{array}{l}0.73 \\
1.86 \\
0.61\end{array}$ & 46.15 & $<0.001^{* *}$ & $\begin{array}{c}<0.001^{* * 1} \\
>0.05 \mathrm{NS}^{2} \\
<0.001^{* * 3}\end{array}$ \\
\hline Number of Hofbauer cells & $\begin{array}{c}\text { Control } \\
\text { PE-IUGR } \\
\text { I-UGR }\end{array}$ & $\begin{array}{l}2.00 \\
8.00 \\
7.50\end{array}$ & $\begin{array}{l}1.07 \\
1.31 \\
1.60\end{array}$ & 49 & $<0.001^{* *}$ & $\begin{array}{l}<0.001^{* * 1} \\
<0.001^{* *_{2}} \\
>0.05 \mathrm{NS}^{3}\end{array}$ \\
\hline
\end{tabular}

SD: Standard deviation F: ANOVA test LSD: Least significant difference

P1: Control versus PE-IUGR P2: Control versus IUGR P3: PE-IUGR versus IUGR NS: Non significant $(P>0.05) \quad *$ : Significant $(P<0.05) \quad * *$ : Highly significant $(P<0.01)$

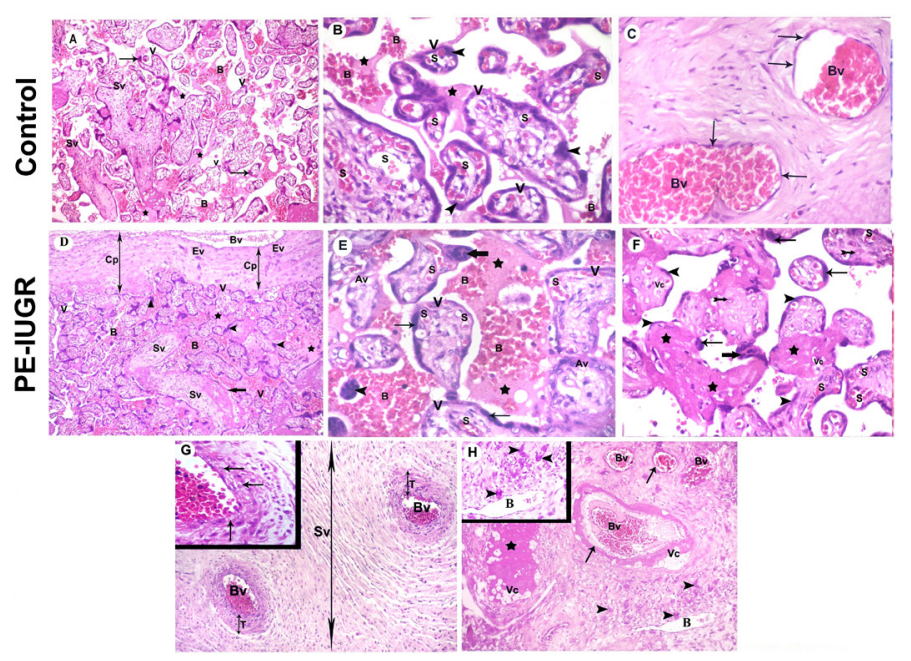

Fig. 1: H\&E-stained sections of group I and group II: (A-C) of group I showing stem(Sv) and terminal villi (V) and maternalblood (B) withacidophilic material (*) in intervillous space.B)Terminalvilli with delicateconnectivetissuecore (v), syncytial knots (arrow head) and numerous sinusoidal capillaries(S). Maternalblood(B)andalittleamountofacidophilic material (*).C) Fetal blood vessels (Bv) with normal endothelial lining (arrow) instem villous. (D - H)of group II showing D)engorgededfetal blood vessel (Bv) and scattered extra-villous trophoblasts $(\mathrm{Ev})$ in apartofchorionicplate(Cp). Stem villi with few blood vessels (Sv) and areas of acidophilic material (arrow). Crowded terminal villi (V) and numerous syncytial knots (arrow head). Abundant acidophilic material (*) and maternal blood (B). E) Some terminal villi (V) with thickened syncytio-vascular membrane (thin arrow) and syncytial sprouts (thick arrow). Few sinusoidal capillaries (S) and avascular villi (Av). Maternal blood (B), acidophilic material (*) and exfoliated syncytial knots (arrow head). F) The cores of some villi are replaced by acidophilic material (*). Few sinusoidal capillaries (S) and vacuolated cells (Vc) and some cells with strong acidophilic cytoplasm (bifid arrow). Villi with thin syncytio-vascular membrane (arrow head), syncytial knots (thin arrow) and sprouts (thick arrow). G) Fetal blood vessels (Bv) with thick walls (T) in a stem villous (Sv). Vacuolated cells in the vascular wall (arrow) in the inset. H) Abnormal maternal blood vessels (Bv), no endothelial lining, pale acidophilic materials (arrows) in their walls and numerous vacuolated cells (Vc). A blood vessel with normal endothelium (B) with scattered extra-villous trophoblasts (arrow head) in inset. (A, D, G, H x100, B, C, E, F x400, inset $\mathrm{x}$ 400). 


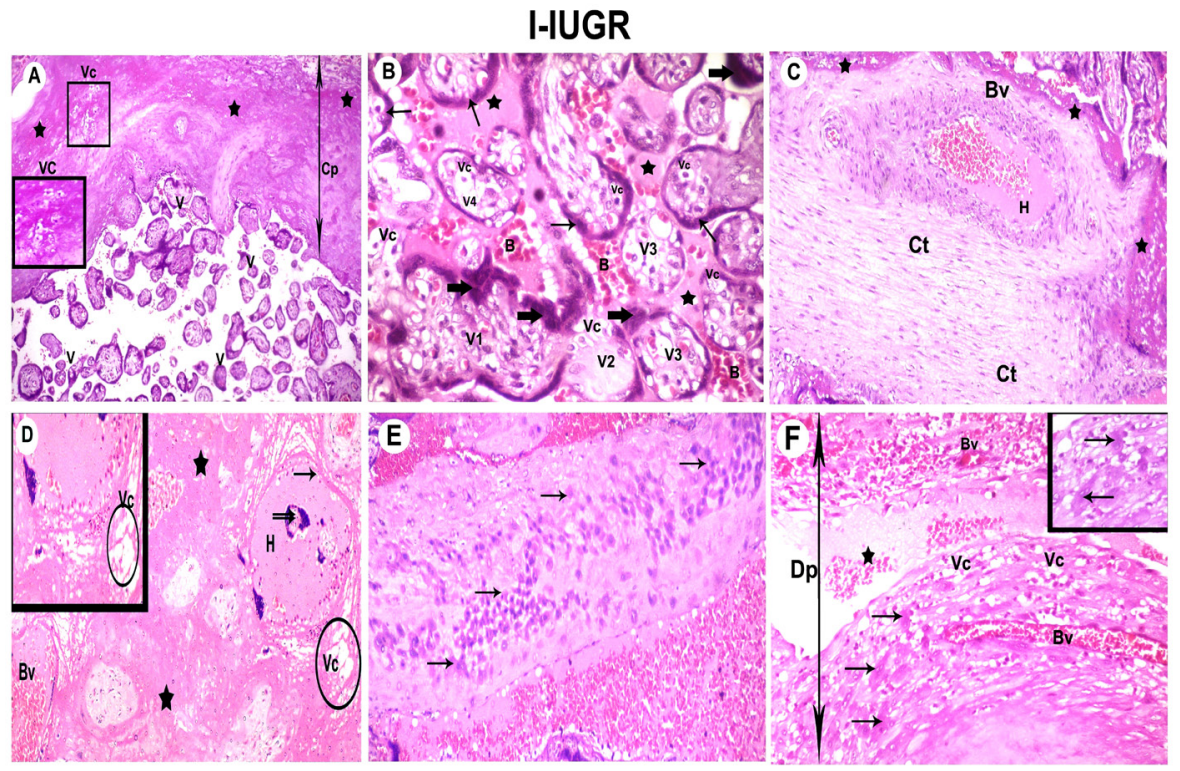

Fig. 2: H\&E-stained sections ofgroup III: showing A) Apartofchorionicplate $(\mathrm{Cp})$ withareasofacidophilic material $(*)$ and vacuolated cells with small darkly stained nuclei $(\mathrm{Vc})$. Widely separated and low vascular terminal villi (V). B) Highly cellular villous core (V1), acidophilic materials in cores of some villi (V2), numerous capillaries in villi (V3) and avascular villi (V4). Syncytial knots (thickarrow), thick syncytio-vascular membrane in some parts (thin arrow) and vacuolated cells (Vc). Acidiophilic material (*) and maternal blood (B). C) A stem villous with connective tissue core $(\mathrm{Ct})$ and peri-villous acidophilic material $(*)$. A congested blood vessel (Bv) with thick wall and luminal pale acidophilic material (H). D) Large areas of acidophilic material (*) and vacuolated cells (Vc). Blood vessels with loss of endothelial lining (arrow), parts of villi with syncytial knots (double arrow), pale homogenous acidophilic materials $(\mathrm{H})$ and congestion $(\mathrm{Bv})$. Perivascular vacuolated cells $(\mathrm{Vc})$ in inset. E) A placental septum with numerous extra-villous trophoblasts arranged in columns. These trophoblasts are irregular or polygonal in shape with darkly stained nuclei (arrow). F) A part of decidual plate (Dp) with extra-villous trophoblasts (arrow), congested blood vessels $(\mathrm{Bv})$, vacuolated cells $(\mathrm{Vc})$ and pale acidophilic material and blood $(*)$. Irregular or polygonal shaped trophoblasts with darkly stained nuclei (arrow) in inset.

(A, C, x100, B, D, E, F x400 inset X 400)



Fig. 3: PAS; A, B, C, MT; D, E, F and CD68 immuno-expression; G, H, I. A)Group I; weak reaction in the villi core (*) and basement membrane of the trophoblasts (arrow). B)Group II; strong reaction in the villi core $(*)$ and basement membrane of the trophoblasts (arrow). Inset, a strong reaction in the lumen (L) and wall of maternal blood vessel (arrow head). C)Group III;strong reaction in both thick syncytiovascular membrane (arrow) and villi core $\left(^{*}\right)$. Inset, A strong reaction in the thick vascular wall (arrow head) and its lumen (L). D)Group I; delicate connective tissue core (arrow head) in terminal villi and thick stroma of stem villi (arrow). E)Group II; abundant fibers (arrow) in the different villi core. F)Group III; extensive fibrous content (arrow head) in the core of terminal and stem villi (arrow). G)Group I; few CD68 expressed cells (arrow) near the syncytio-vascular membrane. Numerous cells near blood capillaries and the syncytio-vascular membrane in Group II(H) and Group III (I).

(A, B, C, D, E, F x200, G, H, I x400 inset X 400) 


\section{DISCUSSION}

According to Raymond and Redline ${ }^{[15]}$ placental lesions were classified into maternal and fetal vascular malperfusion lesions. They reported that the maternal vascular lesions included: increased syncytial knots, increased fibrinoid surface area and also decidualarteriopathy (absence of physiological remodeling, mural hypertrophy, fibrinoid necrosis of the wall, thrombosis, inflammatory and vacuolated cells infiltrations and acute atherosis). They stated that the fetal vascular lesions included: chorionic plate or stem villous thrombi and 3 or more foci of 2-4 avascular villi in a single field. The diameter of the terminal villi was used in our study as an indicator of distal villous hypoplasia.

This study reported significantly lower birth and placental weights in the PE-IUGR group when compared to the control and I-IUGR groups. These data are in agreement with those reported by some studies ${ }^{[23]}$, who defined placental weight as a significant positive predictor for body weight. Many researchers ${ }^{[2]}$ mentioned that in IUGR cases, the mean placental weight was less than the 10th percentile. Placental weight is functionally significant as it is related to villous surface area and fetal metabolism ${ }^{[25]}$. In line with these findings, other studies $^{[26,27]}$ found that the placental diameter, thickness, number of cotyledons, surface area was significantly lower in placentas of PE than in that of controls.

Changes in the decidual blood vessels were the most important findings in the PE-IUGR group. Defective spiral arterioles with narrow lumen were detected by Nelson et $a l^{[28]}$ in placentas of patients diagnosed with early onset preeclampsia. They described the acellular acidophilic material replacing the wall as fibrinoid necrosis. They also reported that the amorphous materials obliterating the lumen as thrombosis and together with the accumulation of the vacuolated cells around the wall the blood vessels they diagnosed these lesions as acute atherosis of the decidual blood vessels. In our study, these findings were found in the control group as a part of the placental maturation process and in the I-IUGR group but they were mild and less frequent. Acute atherosis was rarely detected in both control and I-IUGR placentas ${ }^{[6]}$. In the current study, theses lesions can be obviously observed in both I-IUGR and PE-IUGR groups but were significantly higher in the PE-IUGR group.

Normally the spiral arteries are invaded by extra-villous trophoblasts that replace their endothelium and smooth muscle converting them into wide tubes not responding to maternal vasomotor control to increase the utero-placental flow, this process is called physiological remodeling. This process is impaired in both PE and I-IUGR ${ }^{[6]}$. Some studies $^{[29]}$ reported that trophoblasts induced vascular smooth muscle apoptosis and reduced their proartherogenic response. The presence of abnormal decidual blood vessels in PE indicate a defect in the function of the trophoblasts or a defect in their interaction with the vascular smooth muscle cells.

Maternal vascular malperfusion results from the abnormal blood flow in the defective spiral arteries. This leads to histological changes called accelerated villous maturation, these lesions include increased syncytial knots and increased inter-villous fibrin ${ }^{[15]}$. In this study these lesions were significantly increased in the PE-IUGR group when compared to the control and I-IUGR groups. These changes were reported by many authors and are mainly caused by impaired utero-placental blood flow and hypoxia $^{[24]}$.

In the present studythe mean number of syncytial knots was significantly higher in PE-IUGR group when compared with the control and I-IUGR groups. Syncytial nuclear aggregates, also referred as knots include the clustering of the syncytiotrophoblast nuclei released to maternal blood ${ }^{[30]}$. They act as bridges to stabilize micro villous membrane against possible membrane structural damage caused by the maternal blood flow ${ }^{[31]}$. They are taken by the maternal circulation into the lungs, engulfed by the pulmonary macrophages and due to their large size they cannot cross the air blood barrier. The uptake of these structures by the maternal macrophages reduces the secretion of cytokines and minimizes the maternal immune response ${ }^{[32]}$. In PE, the normal process of syncytial knots formation and phagocytosis is impaired due to hypoxia resulting in apoptosis and syncytial injury. Syncytiotrophoblast micro particles (STM) are released in the maternal circulation and due to their small size they can pass the maternal pulmonary circulation stimulating a maternal immune response leading to endothelial activation and pre-eclampsia ${ }^{[33]}$. This is one of the theories explaining the pathogenesis of PE. These particles were not increased in I-IUGR $^{[34]}$, which coincides with our results as the syncytial knots are not significantly increased in I-IUGR. This may partly explain the absence of the maternal symptoms in cases of I-IUGR.

In our study the fibrinoid surface area was significantly higher in the PE-IUGR group when compared to the control and I-IUGR group. In PE defective cytotrophoblast proliferation results in fibrinoid accumulation in the inter-villous space. Excess fibrinoid limits nutrient and gas exchange leading to more hypoxia and fetal growth restriction $^{[35,36]}$. It is reported that this situation may cause intrauterine growth restriction (IUGR) and that it should especially be searched for in recurrent IUGR ${ }^{[37]}$.

In the PE-IUGR group fetal blood vessels were affected; some were engorged with blood and lost their endothelial lining. Others had thick wall and small acidophilic plaques partially obliterating their lumen. In addition some stem villi were avascular and some contained wide areas of hyaline material. These findings were in agreement with 
Kim et al. ${ }^{[38]}$; they reported that the total number of affected vessels and the number of vessels containing thrombus are directly related to the severity of PE symptoms.

In this study the mean diameter of the terminal villi was significantly lower in the I-IUGR group when compared with the control and PE-IUGR groups resulting in a slender less branched villi which is a characteristic feature in I-IUGR. Defective villous development and angiogenesis which was probably due to shorter and fewer capillary segments was reported by other studies ${ }^{[39]}$ in IUGR but not in PE. Branching morphogenesis of the villous tree follows angiogenesis, new terminal villi are formed over new capillary loops ${ }^{[40]}$, impairment of angiogenesis leads to the formation of smaller, hypo-vascular terminal villi like those observed in this study.

In the current study increased amount of collagen fibers were detected in the different villi of PE-IUGR and IUGR groups. Some researchers ${ }^{[4]}$, reported that villi of pre-eclamptic placentae showed condensed villous connective tissue core and regression of villous capillaries up to complete disappearance. This could be attributed to placental ischemia and increased levels of anti-angiogenic factor soluble fms-like tyrosine kinase-1 (sFlt-1). This consequently may decrease uterine, placental and vascular matrix metalloproteinase- 2 and -9 , leading to increased utero-placental and vascular collagen ${ }^{[42]}$.

The present study revealed strong PAS reaction in thick villous basement membrane. Thickening of the villous basement membrane was reported in PE and hypertensive pregnancies $^{[43,44]}$. Cytotrophoblast cells secrete basement membrane protein as a response to placental ischemia and thickened basement membrane is a byproduct of cytotrophoblast cell proliferation. This leads to high percentage of villi with thickened basement membrane and fetal ischemia ${ }^{[45]}$

Fetal vascular mal-perfusion criteria were significantly higher in the I-IUGR however chorionic plate vascular obliteration and extensive avascular villi were not frequent. The most characteristic finding in this group was stem vessels thrombi partially obliterating the lumen. These lesions were not sufficient to diagnose these cases as fetal vascular mal-perfusion. They were better described as findings consistent with fetal vascular mal-perfusion. Similar results were reported in few studies, like that done by kovo et $a l^{[46]}$,where changes caused by fetal vascular mal-perfusion were more in IUGR cases without preeclampsia. However fetal vascular changes and its role in the pathogenesis of I-IUGR need more investigation.

In our study the number of Hofbauer cells (HBC) was increased in both PE-IUGR and I-IUGR similar results were obtained by ${ }^{[4]}$. HBC are polarized cells they secrete pro-angiogenic and mitogenic factors supporting endothelial cells and endothelial network formation of the early fetal blood vessels they secrete vascular endothelial growth factor (VEGF) and fibroblast growth factor $(\mathrm{FGF})^{[48]}$. They also express sprout proteins (Spry) that enhances angiogenesis and branching of the villous tree ${ }^{[49]}$. In pre-eclampsia, many cytokines are secreted by $\mathrm{HBC}$ and they are reported to induce angiogenesis ${ }^{[00]}$. Previous research showed that abnormal angiogenesis is correlated with the impaired placental and fetal development seen in complicated pregnancies such as $\operatorname{IUGR}^{[51]}$. Structural evidence suggests that placental oxygenation is important in controlling feto-placental angiogenesis and hence, villous differentiation ${ }^{[40]}$. Insufficient uteroplacental perfusion leading to abnormal angiogenesis may result in the pathophysiology of IUGR ${ }^{[51]}$.

The exact pathogenesis of PE and IUGR is not completely understood. Many authors suggested that both conditions begin with a shallow placentation and defective remodeling of the spiral arteries resulting in hypoxia and oxidative stress ${ }^{[52]}$. Placental ischemia and oxidative stress lead to the release of placental factors or stimuli that mediates the maternal inflammatory response and the endothelial dysfunction ${ }^{[53]}$. Normally the pregnancy is characterized by a mild degree of maternal vascular inflammatory response, in cases predisposed to PE or IUGR this normal response is exaggerated ${ }^{[52]}$. Markers of endothelial cell activation e.g. E-selectin and vascular cell adhesion molecules (VCAM) are elevated in preeclampsia and idiopathic IUGR but is higher in $\mathrm{PE}^{[54]}$, raised cytokine levels are reported in PE only ${ }^{[55]}$. Recent reports suggest that maternal predisposition is an important factor in the pathogenesis of PE like maternal metabolic syndrome ${ }^{[56]}$. PE complicated by IUGR results from the combination of both poor placentation and maternal predisposition and it always results in an early onset and severe form with marked maternal and fetal morbidity and mortality ${ }^{[52]}$. These data suggested that IUGR may represent an earlier stage of PE whereas pathogenesis stops at certain point giving the picture of isolated IUGR with minimal maternal symptoms.

In summary, we found that PE-IUGR and I-IUGR cases in this study share common histological changes suggesting a similar pathogenesis. Maternal malperfusion lesions predominate in PE; decidual vascular changes were higher in PE-IUGR resulting in more hypoxia and more growth restriction. Findings consistent with fetal vascular malperfusion especially stem vessels partial obliteration were higher in I-IUGR. Small and slender terminal villi were more frequent in I-IUGR suggesting defective branching morphogenesis. However I-IUGR, fetal vascular malperfusion lesions and Hofbauer cells are understudied and need further investigations.

\section{CONCLUSION}

From our study, we concluded that abnormal uteroplacental blood vessels and chronic utero-placental 
insufficiency and the resulting histological changes in the chorionic villi, inter-villous and/or feto-placental vasculature, and chronic inflammatory lesions may be the primary processes leading to the placental pathology in PE and IUGR. Although the cause of IUGR pregnancies is heterogeneous, careful clinic-pathologic correlations in individual cases are necessary in the interpretation of placental lesions of IUGR, and the cumulative effects of several placental lesions are likely to be more important than a single histologic change.

\section{LIMITATIONS OF THE STUDY}

1- Small number of cases which was due to the strict exclusion criteria of the patients to exclude other causes of IUGR, and the difficult diagnosis of I-IUGR.

2- Finding matching gestational age controls especially for the cases of PE with low gestational age. We included IUGR cases with the highest possible gestational age and control cases with the lowest possible gestational age.

3- The placental bed which is the site where the pathogenesis of both conditions begins was not included; samples from the placental bed may be obtained during caesarian section which could be the subject of further studies.

\section{CONFLICT OF INTEREST}

There are no conflicts of interest.

\section{REFERENCES}

1. Carter AM. "Evolution of placental function in mammals: the molecular basis of gas and nutrient transfer, hormone secretion, and immune responses," Physiol Rev. 2012; 92(4):1543-1576.

2. Burton $\mathrm{G}$ J, Yung $\mathrm{H}$ W, Davis $\mathrm{T}$ C, Jones D $\mathrm{S}$. placental endoplasmic reticulum stress and oxidative stress in the pathophysiology of unexplained intrauterine growth restriction and preeclampsia. Placenta. 2009; 23: S43-S48.

3. Sankaran S, Kyle PM. Etiology and pathogenesis of IUGR. Best Pract Res ClinObstetGynaecol. 2009; 23(6):765-77.

4. Barros FC, Barros AJD, Villar J, Matijasevich A, Domingues MR, Victora CG. How many low birth weight babies in low- and middle-income countries are preterm? Rev SaúdePública. 2011; 45(3):607-1

5. El-Baz MA, El-Deeb TS, El-Noweihi AM, Mohany KM, Shaaban OM, Abbas AM. Environmental factors and apoptotic indices in patients with intrauterine growth retardation: a nested casecontrol study. Environ Toxicol Pharmacol. 2015; 39(2):589-96.

6. Kaufmann P, Black S, Huppertz B. Endovascular trophoblast invasion: implication for the pathogenesis of intrauterine growth retardation and preeclampsia. Bio Reprod. 2003; 96:1-7.

7. Amaral, L. M., Wallace, K., Owens, M., and LaMarca, B. Pathophysiology and current clinical management of preeclampsia Curr Hypertens Rep, 2017; 19(8), 61. Doi: $10.1007 /$ s11906-017-0757-7

8. Al-Jameil, N., Khan, F. A., Khan, M. F., Tabassum, H.. A brief overview of preeclampsia," Journal of Clinical Medicine Research. 2014; 6 (1): 1-7

9. Bilano VL, Ota E, Ganchimeg T, Mori R, Souza JP. Risk factors of pre-eclampsia/eclampsia and its adverse outcomes in low-and middle-income countries: a WHO secondary analysis. PLoS One. 2014; 9:e91198.

10. Grotegut C A. Prevention of preeclampsia. J Clini Invest. 2016; 126 (12), 4396-4398.

11. Huppetz B. Placental origin of preeclampsia: Challenging the current hypothesis. Hypertension. 2008; 51: 970-975.

12. Egbor M, Ansari T, Morris N, Green C, Sibbons P. Morphometric placental villous and vascular abnormalities in early- and late-onset pre-eclampsia with and without fetal growth restriction. BJOG. 2006; 113:580-589.

13. Tolcher, M. C., Chu, D. M., Hollier, L. M., Mas-trobattista, J. M., Racusin, D. A., Ramin, S. M., Aagaard, K. M. Impact of USPSTF recommendations for aspirin for prevention of recurrent preeclampsia. Am J Obstet Gynecol. 2017; 217(3), 365.e1-365.

14. Tang Z, Abrahams VM, Mor G, Guller S. placental hofbauer cells and complications of pregnancy. Ann NY Acad Sci. 2011; 1221:103-108.

15. Raymond W, Redline MD. Classification of placental lesions. Am J Obstet Gynecol. 2015; 213(4 Suppl): s21-s28.

16. Khong TY, Mooney EE, Ariel I,Balmus NC, Boyd TK, Brundler MA et al. Sampling and definitions 
of placental lesions. Amsterdam placental workshop group consensus statement. Arch Path Lab Med. 2016; 14: 698-713.

17. Veerbeek JH, Nikkels PG, Torrance HL, Gravesteijn J, Post Uiterweer ED, Derks JB, Koenen SV, Visser GH, Van Rijn BB, Franx A. Placental pathology in early intrauterine growth restriction associated with maternal hypertension. Placenta. 2014; 35: 696-701.

18. http://dempuegypt.blogspot.com/2008/11/ egyptian-gorwth-curves-boys-birth_28.html

19. http://dempuegypt.blogspot.com/2008/11/ egyptian-gorwth-curves-girls-birth_28.html

20. Sibai BM. Diagnosis and management of gestational hypertension and preeclampsia. Obstet Gynecol. 2003; 102:181-192.

21. Bancroft, J.D., Layton, C., The Hematoxylins and Eosin. Bancroft's Theory and Practice of Histological Techniques, Expert Consult: Online and Print, 7: Ban-croft's Theory and Practice of Histological Techniques. 2012; Elsevier, pp. 173.

22. Kunisch E, Fuhrmann R, Roth A, Winter R, Lungershausen W, Kinne RW. Macrophage specificity of three anti-CD68 monoclonal antibodies (KP1, EBM11, and PGM1) widely used for immunohistochemistry and flow cytometry. Ann Rheum Dis. 2003; 63(7): 77.

23. Salama GA, Alama OA, , Ahmeda UF, AlSherbenyb MF. Light and electron microscopic study of placenta in pre-eclampsia: a trial to define underlying changes and its clinical impact. Tanta Med J. 2015; 43:134-145.

24. Roberts DJ, Post MD. The placenta in preeclampsia and intrauterine growth restriction. J ClinPathol. 2008; 61:1254-60.

25. Udaina A, Bhagwat SS, Mehta CD. Relation between placental surface area, infarction and fetal distress in pregnancy induced hypertension with its clinical relevance. J AnatSoc India. 2004; 53(1):27-30.

26. Nahar L, Nahar K, Hossain MI, Jahan S, Rahman MM. Placental changes in pregnancy induced hypertension. Mymensingh Med J. $2013 ; 22: 684-693$.

27. Sankar KD, Bhanu PS, Ramalingam K, Kiran S, Ramakrishna BA. Histomorphological and morphometrical changes of placental terminal villi of normotensive and preeclamptic mothers. Anat Cell Biol. 2013; 46:285-290.

28. Nelson DB, Ziadie MS, McIntire DD, Rogers $\mathrm{BB}$, Leveno KJ. Placental pathology suggesting that preeclampsia is more than one disease. Am J Obstet and Gynecol. 2014; 66e1-66e7.

29. Hering L, Herse F, Park JK, Verlohren S. Trophoblasts Reduce the Vascular Smooth Muscle Cell Proatherogenic Response. Hypertension. 2008;51(2):554-559.

30. Tanetta D, Masliukaite I, Vatish M, Redman C and Sargent I. Update of syncytiotrophoblast derived extracellular vesicles in normal pregnancy and preeclampsia. J ReprodImmunol. 2017; 119:98e-106.

31. Calvert SJ, Jones CJ, Sibley CP, Aplin JD, Heazell AE. Analysis of syncytial nuclear aggregates in preeclampsia shows increased sectioning artifacts and decreased inter-villous bridges compared to healthy placentas.Placenta. 2013; 34:1251e-1254.

32. Huppetz B. Placental origin of preeclampsia: Challenging the current hypothesis. Hypertension. 2008; 51: 970-975.

33. Gupta A K, Rusterholz C Huppertz, B. A comparative study to the effect of three different syncytiotrophoblast micro-particles preparations on endothelial cells. Placenta. 2005; 26: 59-66.

34. Goswami D, Tannetta DS, Magee LA. Excess syncytio-trophoblast micro-particle shedding is a feature of early-onset pre-eclampsia but not normotensive intrauterine growth restriction. Placenta. 2006; 27: 56-61.

35. Matejevic D, Neudeck H, Graf R, Müler T, Diet J. Localization of hyaluronan with a hyaluronanspecific hyaluronic acid binding protein in the placenta in preeclampsia. GynecolObstet Invest. 2001; 52(4):257-259.

36. Myatt L. Role of placenta in preeclampsia. Endocrine. 2002; 19(1):103-111.

37. Roberts DJ. The placenta in pre-eclampsia and intrauterine growth restriction. J CliniPathol. 2008; 61:1254-60.

38. Kim Y, Chaemsithong P, Romero R. The frequency of acute atherosis in normal pregnancy, preterm labor, preeclampsia, small for gestational 
age, fetal death and mid-trimester spontaneous abortion. J Matern fetal Neonatal Med. 2015; 28 (17): 2001-2009.

39. Mayhew TM, Charnock-Jones DS, Kaufmann P. Aspects of human feto-placental vasculogenesis and angiogenesis. III. Changes in complicated pregnancies. Placenta. 2004; 25:127-139.

40. Kaufmann P, Mayhew TM. CharnockJones JS. Aspects of human feto-placental vasculogenesis and angiogenesis. Placenta. 2004; 25(2-3):114-126.

41. Awadallah R, Dkhil MA. Structural Changes of Placenta in Pre-eclamptic Patients: Light and Electron Microscopic Study. Turk J Med Sci. 2008; 38 (3):219-225.

42. Li W, Mata KM, Mazzuca MQ, Khalil RA. Altered matrix metalloproteinase-2 and -9 expression/activity links placental ischemia and anti-angiogenic sFlt-1 to uteroplacental and vascular remodeling and collagen deposition in hypertensive pregnancy. Biochem Pharmacol. 2014; 89(3):370-85.

43. Narasimha A, Vasudeva DS. Spectrum of changes in placenta in toxemia of pregnancy. Indian $\mathrm{J}$ PatholMicrobioL. 2011; 54: 15-20.

44. Pasricha N, Nagar A, Gupta A. Histological changes in placentae in pregnancies complicated by pre-eclampsia and eclampsia and correlation with fetal outcome. Int J Pharm Bio Sci. 2012; 3(2):551-560.

45. Ansari H, Singh A, Zaidi TM , Chandra N. Vasculo-syncytial membrane in placental villi of normotensive and hypertensive pregnancies. J AnatSoc India. 2011; 60(2):168-170.

46. Kovo M, Schreiber L, Ben-Haroush A. Placental vascular lesions differences in pregnancyinduced hypertension and normotensive fetal growth restriction. Am J Obstet Gynecol. 2010; 202(6):561.e1-561.e5.
47. Nasir A, Nergiz Y, Aktas A and Akdeniz N. Light microscope evaluation of iron accumulation in term placentas of subjects with preeclampsia. Afr J Biotechnol. 2011; 10(54): 11273-11279.

48. Loegl J, Hiden U, Nussbaumer E. Hofbauer cells of $\mathrm{M} 2 \mathrm{a}, \mathrm{M} 2 \mathrm{~b}$ and $\mathrm{M} 2 \mathrm{c}$ polarization may regulate feto-placental angiogenesis. Reproduction. 2019; 152(5): 447-455.

49. Anteby E, Natason-Yaron S, Greenfeild C. Human placental Hofbauer cells express sprout protein: a possible modulating mechanism of villous branching. Placenta. 2005; 26(6): 476-483.

50. Albrecht ED, Robb VA, Pepe GJ. Regulation of placental vascular endothelial growth/ permeability factor expression and angiogenesis by estrogen during early baboon pregnancy. J ClinEndocrinolMetab. 2004; 89(11): 5803-09.

51. Arroyo JA, Winn VD.Vasculogensis and angiogenesis in the IUGR placenta. SeminPerinatol. 2008;32(3): 12-176.

52. Staff AC, Benton SJ, Daelszen P. Redefining preeclampsia using placenta-derived biomarkers. Hypertension. 2013; 61: 932-942.

53. Roberts JM, Hubel CA. The two stage model of preeclampsia: Variation on the theme. Placenta. 2009; 30(Suppl A): S32-S37.

54. Bretelle F, Sabtier F, Blann A. Maternal endothelial cell soluble adhesion molecules with isolated small for gestational age fetuses: comparison with preeclampsia. $\mathrm{Br}$ J Obs Gyn. 2001; 108: $1277-1282$.

55. Johnson MR, Nyame N, Johnson P. Does endothelial cell activation occur with intrauterine growth restriction? Br J Obs Gyn. 2002; 109: 836-839.

56. Ness RB and Sibai BM. Shared and disparate components of the pathophysiologies of fetal growth restriction and preeclampsia. Am J Obs Gyn. 2006; 195: 40-49. 
الملخص العربى

التغيرات النسيجيه في مشيمه الانسان في حالات تاخر النمو داخل الرحم في وجود او عدم وجود

ايمان محمود عسكر1، سالي احمد سليم ، هدي السباعي²

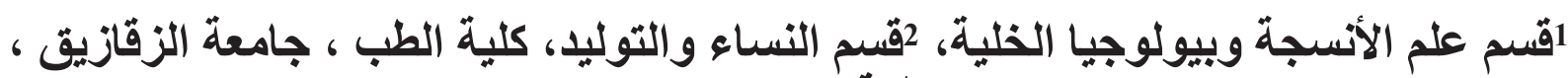
الزقازيق، مصر







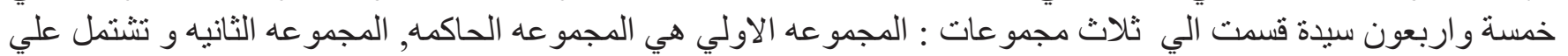
حالات تاخر النمو داخل الرحم الناتجه عن تسمم الحمل, المجمو عه الثالثه تشتمل علي حالات تاخر النمو داخل الرحم بدون سبب التبه

$$
\text { واضح. }
$$

الطرق و المو اد المستخدمة: تم فحص عينات المشيمه من كل الحالات بالفحص النسيجي و القياسات المورفومثريةو الهستو كيميائية.

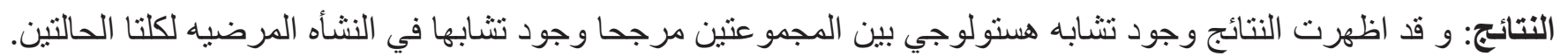

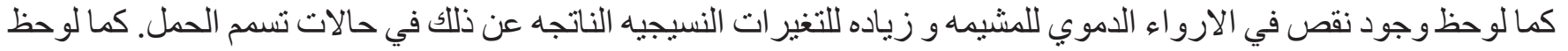

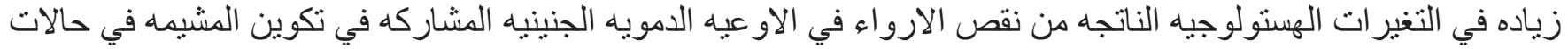

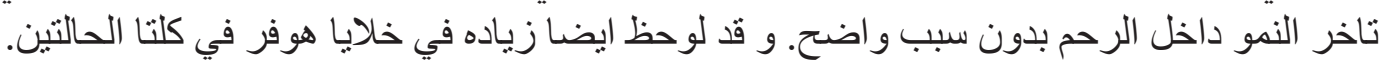

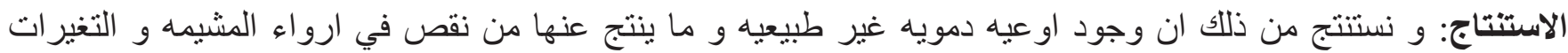

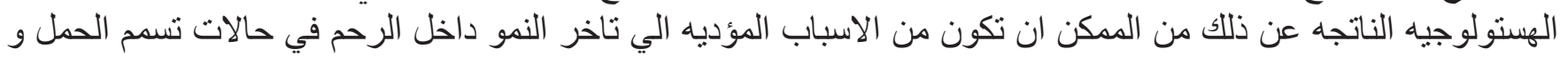
كذلك في الحالات الغير محدده الاسباب. 